\title{
Socio-Economic Status, Hygiene Practices and Microbial Exposure of the Waste Collectors of Dhaka City in Bangladesh
}

\author{
M. A. Rifat ${ }^{1}$, Asit Biswas ${ }^{1}$, Hazera Binte Sufian ${ }^{1},{\text { Faria } \text { Azad }^{1} \& \text { MD Khurshidul Zahid }}^{1}$ \\ ${ }^{1}$ Institute of Nutrition and Food Science, University of Dhaka, Bangladesh \\ Correspondence: M. A. Rifat, Research Assistant, Institute of Nutrition and Food Science, University of Dhaka, \\ Dhaka-1000, Bangladesh. Tel: 88-016-84-774-313. E-mail: rifatahmed011@gmail.com
}

Received: September 4, 2018 Accepted: November 6, 2018 Online Published: November 15, 2018

doi:10.5539/gjhs.v10n12p96

URL: https://doi.org/10.5539/gjhs.v10n12p96

\begin{abstract}
Waste is a discarded part generated from primary use of a material. In most cases, waste is very much unwanted and unusable but may be usable and beneficial for our economy and environment. Waste collectors are playing vital roles for the management of wastes though they are deprived of their basic needs. They are involved directly or indirectly to our economy and environmental development. However, whether waste collection activity has any effect on the socioeconomic status, hygiene practices, and microbial exposure of waste collectors remain unknown. Here we investigated socio-economic status, hygiene practices and microbial exposure of the waste collectors of Dhaka city in Bangladesh.

This study included two types of waste collectors in Dhaka city. One is the household waste collectors (HWCs) who belong to the formal waste management system of the city corporation and the other is the street waste collectors (SWCs) who belong to the informal waste management system that is executed mainly by the vulnerable groups of people locally called "Tokai". The total sample size was 150 ( 75 HWCs and 75 SWCs) who were randomly selected from 15 different sites (clusters) of the city. The research findings showed that $20 \%$ waste collectors were children and $76.67 \%$ were illiterate. The majority $(72.7 \%)$ earned less than $150 \mathrm{BDT} / \mathrm{day}$ but the lion's share was spent on food. The coverage of sanitary toilet facility was $42.0 \%$ whereas $70.7 \%$ SWCs had no toilet facility. The majority $(82.7 \%)$ used to drink untreated water and $41.3 \%$ had disease episode in previous 30 days of data collection time. Only $28.0 \%$ waste collectors had bathing facility at home. Noticeably, no waste collector was wearing mask, gloves and apron while handling the waste. Analysis found that the status of HWCs was better than that of SWCs. Association among the variables showed that significant relationship existed between income level and percentage of expenditure on foods, types of drinking water and disease episode in previous 30 days, types of toilet used and hand washing practices. Microbiological analysis showed that the waste collectors were more exposed to the microbial hazards than the normal people.

HWCs and SWCs included in this study belong to vulnerable groups of Bangladesh. They are playing vital roles for cleaning and developing environmental conditions and living standards of Dhaka city though their contributions were mostly unrecognized. The present results suggested that socio-economic status, hygiene practices and microbial exposure of waste collectors of Dhaka city in Bangladesh are in poor and critical conditions. To address the present needs, proper measures should be taken by the coordinated activities (short and long-term) of both govt. and non-govt. organizations.
\end{abstract}

Keywords: waste collectors, socio-economic status, hygiene, sanitation, Dhaka city

\section{Introduction}

Dhaka is one of the most overcrowded cities in the world. Due to rapid population influx, the number of people in Dhaka is increasing but the majorities are with low socio-economic status (Hossain, 2008). The factors hastening the urbanization process lead the generation of huge waste or discarded materials causing environmental degradation and extensive effort required to manage these waste materials produced in Dhaka (Dewan, Kabir, Nahar, \& Rahman, 2012; Enayetullah, 1994). This study included two types of 'waste collectors' (or pickers) defined as the household waste collectors (HWCs) and the street waste collectors (SWCs). HWCs collected waste from the households and mainly worked in the dumping zones by monthly payment. They were the part of the city corporation's traditional waste management system. On the other hand, SWCs were the part of informal waste management system and collect waste materials from various public places thrown by the people. They are locally called "Tokai". Waste collectors are a heterogeneous population group who deliberately contribute to the waste management by sorting, segregating, and recycling collected wastes. But, in many areas around the world, their works often go unrecognized by the policy makers (Waste Pickers without Frontiers, 2008). Municipalities often 
consider waste collectors a problem although they are environmentally and economically important (Dias, Sonia, 2008; SEWA, 2010). A large number of people in developing countries, which includes about one percent of urban people, have to survive by collecting recyclable materials from wastes. Fundamentally there are many economic factors which pushed them into collecting wastes. They lead their lives in an unfavorable environment such as limited availability and accessibility to the existing facilities and rejection by the society people. They worked on the street sides, in open dumps, in the slum areas, stations, where they had to contact with all kinds of dirty, hazardous, infectious wastes on a regular basis that brought them into serious health risks and ultimately made them the most vulnerable (Cointreau \& Sandra, 2006). Socioeconomic status determines the availability and accessibility of the existing resources and facilities in terms of income, education, family structure, family wealth, access to health care services, access to good hygiene and sanitation, access to social amenities such as television and mobile phone which were considered as indices of the socioeconomic status in this study (Graetz, 1995; Krieger, Nancy, David \& Nancy, 1997; Marks, 1998; Elo \& Preston, 1996).

Hygiene refers to behavioral practice which breaks the transmission of disease (AHMED, Khan, \& Alam, 2000). People are potential sources of microorganisms that cause illness among the others through transmission of these microorganisms in various ways (Wise, 1979). Good hygienic behavior is necessary for preventing the infectious diseases caused from contaminated water and poor sanitary practices. On an average, good hygiene and sanitation practices could reduce $65 \%$ death due to diarrheal diseases that is considered a universal problem as well as a potential cause of child death (Boschi-Pinto, Velebit \& Shibuya, 2008; WHO Health Statistics, 2008). But, approximately $14-40 \%$ diarrheal diseases can be reduced by proper hand washing practices (Hoque, 2003). On the other hand, sanitation is a method aimed at decreasing the spread of infections by proper disposal of waste water and excreta, improved food and beverage management systems, and addressing factors related to diseases (Winblad \& Simpson-Hebert, 2004). Sanitation is a big concern especially in the urban areas of Bangladesh because the accessibility of pure water supply in the urban areas was decreased to $85 \%$ in 2008 from $88 \%$ in 1990 . About $58 \%$ of all urban poor suffers from water-hygiene-sanitation related diseases (ICDDR'B, 2014). Behavior is an important issue regarding hygiene and sanitation because it can convert the knowledge into practices. Hygiene behavior in Bangladesh required improvement because the rate of appropriate hand washing practice was only $27 \%$ in Bangladesh and 32\% in Dhaka (Helen Keller International \& James P. Grant School of Public Health, 2016). Whatever, there are some commonalities among the waste collectors such as they are unprotected and unorganized, with low and inconsistent income, and exposed to potential health hazards and unhygienic conditions. The policies of the government are very much unfriendly for the waste collectors to sustain their livelihoods properly (Salam, 2001).

\subsection{Objective of the Study}

This study primarily aimed at assessing the socio-economic status, hygiene and sanitation practices, and microbial exposure of the waste collectors of Dhaka city in Bangladesh. Another objective was to observe the differences between HWCs and SWCs in terms of the indicators studied.

\subsection{Hypothesis}

Null hypothesis $\left(\mathbf{H}_{\mathbf{0}}\right)$ : No significant difference is present between HWCs and SWCs in terms of their socio-economic status, hygiene and sanitation practices.

Alternative hypothesis $\left(\mathbf{H}_{1}\right)$ : Significant difference is present between HWCs and SWCs in terms of their socio-economic status, hygiene and sanitation practices.

\section{Methodology}

\subsection{Study Design and Study Period}

The study was a cross-sectional study. Data were collected from the target population through direct interview and physical observation during the period of January 2013 to March 2013. Overall study period was November 2012 to June 2013.

\subsection{Sample Size and Sampling Technique}

Total sample size was 150 ( 75 HWCs and 75 SWCs) who were randomly chosen for data collection by face-to-face interviews from 15 different areas (clusters) of Dhaka city in Bangladesh. Areas included in this study were (1) Dhaka University (DU) Campus, (2) Dhaka Medical College (DMC) campus, (3) Anando Bazar, Changkhar Pul Area, (4) Jurain, Postagola, (5) South Jatrabari, (6) Dholaikhal, Noya-bazaar, (7) Gulistan, (8) Komolapur, Motijhil, (9) Maniknagar, (10) Kajla, Demra, (11) Hatirpul and Panthpath, (12) Uttara, (13) Tejgaon, (14) Bashabo, and (15) Neelkhet

\subsection{Data Collection and Analysis}

Data were collected by direct interviewing the participants at their workplaces and the answers were coded in the 
questionnaires. Sometimes data credibility was confirmed by household visits. On everyday basis, the data were checked, validated, and entered into the SPSS (version 16.0 SPSS Inc, Chicago, IL, USA) for statistical analysis. Analysis was done to compare the differences and association among different variables present in HWCs and SWCs by t-test and Chi-square test.

\subsection{Microbial Sample Analysis}

To observe the microbial exposure, liquid samples (hand washed water) were collected from selected HWCs, SWCs, and normal subjects. Then serial dilution technique was used to facilitate growth and determination of the number of microorganism in plate count agar (PCA) media. Finally, total number of colony forming unit (cfu) was calculated. Microbial samples were also collected from the randomly selected subjects in identical way from the same location and at same time point of data collection.

\subsection{Ethical Issues}

Ethical guidelines of Declaration of Helsinki IV (2001) were followed in this study. The questionnaire was designed considering the privacy of the subjects. The subject's personal information was kept confidential. All the sampled respondents agreed to take part in the study that gave a consent rate of $100 \%$.

\section{Results}

Socio-demographic findings showed that most of the waste collectors were adult and a significant portion of them were children. Majority of the married waste collectors (76.3\%) got married before 21 years of age. Only $28 \%$ HWCs and $18.7 \%$ SWCs were literate. Majority (72.7\%) had daily income below 150 BDT whereas the lion's share was spent on food. Except daily income, distribution of other indicators significantly varied between HWCs and SWCs.

Table 1. Distribution (\%) of the socio-demographic variables

\begin{tabular}{|c|c|c|c|c|}
\hline Indicators & $\begin{array}{l}\text { HWCs } \\
(n=75)\end{array}$ & $\begin{array}{l}\text { SWCs } \\
(n=75)\end{array}$ & $\begin{array}{l}\text { Total } \\
(n=150)\end{array}$ & P-value \\
\hline \multicolumn{5}{|l|}{ Age } \\
\hline$<18$ years & $12.0 \%(9)$ & $29.3 \%(22)$ & $20.7 \%(31)$ & \multirow{2}{*}{$0.009^{*}$} \\
\hline$\geq 18$ years & $88.0 \%(66)$ & $70.6 \%(53)$ & $79.3 \%(119)$ & \\
\hline \multicolumn{5}{|l|}{ Sex } \\
\hline Male & $81.3 \%(61)$ & $72.0 \%(54)$ & $76.7 \%(115)$ & \multirow{2}{*}{$0.177^{*}$} \\
\hline Female & $18.7 \%(14)$ & $28.0 \%(21)$ & $23.3 \%(35)$ & \\
\hline \multicolumn{5}{|l|}{ Marital status } \\
\hline Married & $65.3 \%(49)$ & $41.3 \%(31)$ & $53.3 \%(80)$ & \multirow{2}{*}{$0.003^{*}$} \\
\hline Unmarried & $34.7 \%(26)$ & $58.7 \%(44)$ & $46.7 \%(70)$ & \\
\hline \multicolumn{5}{|c|}{ Age at first marriage $(n=80)$} \\
\hline$<21$ year & $70.8 \%(34)$ & $81.8 \%(27)$ & $76.3 \%(61)$ & \multirow{2}{*}{$0.163^{*}$} \\
\hline$\geq 21$ year & $29.3 \%(14)$ & $15.2 \%(5)$ & $23.7 \%(19)$ & \\
\hline \multicolumn{5}{|l|}{ Literacy rate } \\
\hline Illiterate & $72.0 \%(54)$ & $81.3 \%(61)$ & $76.7 \%(115)$ & \multirow{2}{*}{$0.177^{*}$} \\
\hline Literate & $28.0 \%(21)$ & $18.7 \%(14)$ & $23.3 \%(35)$ & \\
\hline \multicolumn{5}{|l|}{ Daily income } \\
\hline $\mathrm{BDT}^{* *} \leq 150$ & $56.0 \%(42)$ & $89.3 \%(67)$ & $72.7 \%(109)$ & \multirow{3}{*}{$0.000^{*}$} \\
\hline $\mathrm{BDT}^{* *} 151-249$ & $37.3 \%(28)$ & $9.3 \%(7)$ & $23.3 \%(35)$ & \\
\hline $\mathrm{BDT}^{* *} \geq 250$ & $6.7 \%(5)$ & $1.3 \%(1)$ & $4.0 \%(6)$ & \\
\hline \multicolumn{5}{|l|}{ Expenditure on food } \\
\hline$\leq 50 \%$ of total income & $26.7 \%(20)$ & $8.0 \%(6)$ & $17.3 \%(26)$ & \multirow{2}{*}{$0.002^{*}$} \\
\hline$>50 \%$ of total income & $73.3 \%(55)$ & $92.0 \%(69)$ & $82.7 \%(124)$ & \\
\hline
\end{tabular}

Data are presented as $\%(n), n=$ number of sample.

Differences were considered to be statistically significant at $P$ values 0.05 or less.

${ }^{*}$ P-value or significant value calculated from chi-square test (at $95 \%$ confidence interval and 5 degrees of freedom).

**77.69 BDT (Bangladeshi Taka) = 1 USD (US Dollar) in the study year. 
Regarding family history, average family size was bigger among the HWCs compare to SWCs who were mainly peripatetic and single in nature (Table 2). Most of the waste collectors were migrated to the Dhaka city from outside. As the SWCs were mainly floating people, $44 \%$ of them did not have any permanent sleeping places and they used to sleep either in the roadsides or in the parks. On the other hand, HWCs mainly slept in the shared rooms. In terms of access to the facility of mobile phone, television, electricity and gas as cooking fuel, HWCs were significantly better than street waste collectors.

Table 2. Distribution (\% or Mean \pm Standard Error of Mean) of the variables regarding family information and access to social facilities

\begin{tabular}{lllll}
\hline Indicators & $\begin{array}{l}\text { HWCs } \\
(\mathbf{n}=75)\end{array}$ & $\begin{array}{l}\text { SWCs } \\
(\mathbf{n}=\mathbf{7 5})\end{array}$ & $\begin{array}{l}\text { Total } \\
(\mathbf{n = 1 5 0 )}\end{array}$ & P-value \\
\hline Average family size & $4.6 \pm 0.22$ & $3.1 \pm 0.28$ & $3.87 \pm 0.17$ & $\mathbf{0 . 0 0 0}^{* * *}$ \\
Migrated from outside Dhaka & $93.3 \%(70)$ & $94.7 \%(71)$ & $94.0 \%(141)$ & $0.731^{*}$ \\
Earning member per family & $2.1 \pm 0.10$ & $1.7 \pm 0.10$ & $1.88 \pm 0.07$ & $\mathbf{0 . 0 0 0}^{* * *}$ \\
Daily working hour & $8.3 \pm 0.10$ & $9.4 \pm 0.17$ & $8.85 \pm 0.1$. & $\mathbf{0 . 0 0 0}^{* *}$ \\
No specific sleeping place & $1.3 \%(1)$ & $44.0 \%(33)$ & $22.7 \%(34)$ & $\mathbf{0 . 0 0 0}^{*}$ \\
Room shared by $\geq 3$ people & $62.7 \%(47)$ & $53.3 \%(40)$ & $58.0 \%(87)$ & $0.247^{*}$ \\
Mobile phone user & $68 \%(51)$ & $8 \%(6)$ & $38.0 \%(57)$ & $\mathbf{0 . 0 0 0}^{*}$ \\
Had television at home & $25.3 \%(19)$ & $12.0 \%(9)$ & $18.7 \%(28)$ & $\mathbf{0 . 0 3 6}^{*}$ \\
Got electricity facility & $100.0 \%(75)$ & $40.0 \%(30)$ & $70.0 \%(105)$ & $\mathbf{0 . 0 0 0}^{*}$ \\
Access to gas as fuel for cooking & $62.7 \%(47)$ & $14.7 \%(11)$ & $38.7 \%(58)$ & $\mathbf{0 . 0 0 0}^{*}$ \\
Used wood or kerosene as fuel & $37.3 \%(28)$ & $54.7 \%(41)$ & $46.0 \%(69)$ & $\mathbf{0 . 0 4 3}^{*}$ \\
Did not use any fuel for cooking & $0 \%(0)$ & $30.7 \%(23)$ & $15.3 \%(23)$ & - \\
Collecting waste for $\geq 5$ years & $52 \%(39)$ & $33.3 \%(25)$ & $42.7 \%(64)$ & $\mathbf{0 . 0 2 1}^{*}$ \\
\hline
\end{tabular}

Data are presented as \% (n), and mean \pm Standard Error of Mean (SEM), $n=$ number of sample.

Differences were considered to be statistically significant at $\mathrm{P}$ values 0.05 or less.

${ }^{*} \mathrm{P}$-value or significant value calculated from chi-square test (at $95 \%$ confidence interval and 5 degrees of freedom).

${ }^{* *} \mathrm{P}$-value or significant value calculated from t-test (at $95 \%$ confidence interval and 5 degrees of freedom).

Hygiene and sanitation practices of the waste collectors showed that only $18.7 \%$ street waste collectors had the sanitary toilet facilities. They mainly used to drink municipality suppled water without any purification. Previous 30 days disease history at the time of data collection showed that morbidity rate was higher among the SWCs $(60.0 \%)$ than the HWCs $(22.7 \%)$. Most of the SWCs $(88.0 \%)$ had no specific bathing facilities. The overall scenario is presented in Table 3. 
Table 3. Distribution (\%) of the variables regarding sanitary facility and morbidity

\begin{tabular}{|c|c|c|c|c|}
\hline Indicators & $\begin{array}{l}\text { HWCs } \\
(n=75)\end{array}$ & $\begin{array}{l}\text { SWCs } \\
(n=75)\end{array}$ & $\begin{array}{l}\text { Total } \\
(n=150)\end{array}$ & P-value \\
\hline \multicolumn{5}{|l|}{ Types of toilet used } \\
\hline Sanitary & $65.3 \%(49)$ & $18.7 \%(14)$ & $42.0 \%(63)$ & \multirow{3}{*}{$0.000^{*}$} \\
\hline Unhygienic & $25.3 \%(19)$ & $10.7 \%(8)$ & $18.0 \%(27)$ & \\
\hline No toilet & $9.3 \%(7)$ & $70.7 \%(53)$ & $40.0 \%(60)$ & \\
\hline \multicolumn{5}{|l|}{ Source of drinking water } \\
\hline Municipality supply & $6.7 \%(5)$ & $2.7 \%(2)$ & $4.7 \%(7)$ & \multirow{4}{*}{$0.000^{*}$} \\
\hline Roadside tap & $4 \%(3)$ & $36.0 \%(27)$ & $20.0 \%(30)$ & \\
\hline Deep tube well & $41.3 \%(31)$ & $21.3 \%(16)$ & $31.3 \%(47)$ & \\
\hline Other sources & $48 \%(36)$ & $40.0 \%(30)$ & $44.0 \%(66)$ & \\
\hline \multicolumn{5}{|l|}{ Types of drinking water } \\
\hline Raw & $70.4 \%(53)$ & $94.7 \%(71)$ & $82.7 \%(124)$ & \multirow{2}{*}{$0.000^{*}$} \\
\hline Purified & $29.6 \%(22)$ & $5.3 \%(4)$ & $17.3 \%(26)$ & \\
\hline \multicolumn{5}{|l|}{ Any illness in last 30 days } \\
\hline Yes & $22.7 \%(17)$ & $60.0 \%(45)$ & $41.3 \%(62)$ & \multirow{2}{*}{$0.000^{*}$} \\
\hline No & $77.3 \%(58)$ & $40.0 \%(30)$ & $58.7 \%(88)$ & \\
\hline \multicolumn{5}{|l|}{ Place of treatment for illness } \\
\hline Public hospital & $54.7 \%(41)$ & $26.7 \%(20)$ & $40.7 \%(61)$ & \multirow{3}{*}{$0.000^{*}$} \\
\hline Pharmacy & $42.7 \%(32)$ & $20.7 \%(20)$ & $34.7 \%(52)$ & \\
\hline Others & $2.7 \%(2)$ & $46.6 \%(35)$ & $24.6 \% 37)$ & \\
\hline \multicolumn{5}{|l|}{ Bathing facility at home } \\
\hline Yes & $44.0 \%(33)$ & $12.0 \%(9)$ & $28.0 \%(42)$ & \multirow{2}{*}{$0.000^{*}$} \\
\hline No & $56.0 \%(42)$ & $88.0 \%(66)$ & $72.0 \%(108)$ & \\
\hline \multicolumn{5}{|l|}{ Bathing place } \\
\hline Specific place/shared bathroom & $82.6 \%(62)$ & $28.0 \%(21)$ & $55.3 \%(83)$ & \multirow{2}{*}{$0.000^{*}$} \\
\hline No specific place & $17.3 \%(13)$ & $72.0 \%(54)$ & $44.7 \%(67)$ & \\
\hline
\end{tabular}

Data are presented as \% (n), $n=$ number of sample.

Differences were considered to be statistically significant at $\mathrm{P}$ values 0.05 or less.

${ }^{*} \mathrm{P}$-value or significant value calculated from chi-square test (at $95 \%$ confidence interval and 5 degrees of freedom).

The level of personal hygiene maintained by the waste collectors was not satisfactory. Most of them (69.3\%) were found with long and dirty finger nails. Only 8.0\% SWCs washed their hands with soap after defecation and 17.3\% of them took bath daily. During working, all the waste collectors maintained as usual contacts like hand-shaking, smoking, eating street foods without washing their hands. Although majority $(68.0 \%)$ was wearing shoes or sandals, nobody was using gloves, mask, and apron while handling the waste. 
Table 4. Distribution (\%) of the variables regarding personal hygiene and sanitary practices

\begin{tabular}{|c|c|c|c|c|}
\hline Indicators & $\begin{array}{l}\text { HWCs } \\
(n=75)\end{array}$ & $\begin{array}{l}\text { SWCs } \\
(n=75)\end{array}$ & $\begin{array}{l}\text { Total } \\
(n=150)\end{array}$ & P-Value \\
\hline Presence of long and dirty fingernails & $54.7 \%(41)$ & $84 \%(63)$ & $69.3 \%(104)$ & $0.000^{*}$ \\
\hline Hand washing with soap after defecation & $50.7 \%(38)$ & $8.0 \%(6)$ & $29.3 \%(44)$ & $0.000^{*}$ \\
\hline Bathing with soap after working & $84.0 \%(63)$ & $16.0 \%(12)$ & $50.0 \%(75)$ & $0.000^{*}$ \\
\hline Daily bathing practice & $92.0 \%(69)$ & $17.3 \%(13)$ & $48.0 \%(72)$ & $0.000^{*}$ \\
\hline Maintained usual contacts during working & $100.0 \%(75)$ & $100.0 \%(75)$ & $100.0 \%(150)$ & - \\
\hline Wear shoes/sandal during working & $85.3 \%(64)$ & $50.7 \%(38)$ & $68.0 \%(102)$ & $0.000^{*}$ \\
\hline Wear glove during working & $0.0 \%(0)$ & $0.0 \%(0)$ & $0.0 \%(0)$ & - \\
\hline Wear mask during working & $0.0 \%(0)$ & $0.0 \%(0)$ & $0.0 \%(0)$ & - \\
\hline Wear apron during working & $0.0 \%(0)$ & $0.0 \%(0)$ & $0.0 \%(0)$ & - \\
\hline
\end{tabular}

Data are presented as $\%(n), n=$ number of sample.

Differences were considered to be statistically significant at $\mathrm{P}$ values 0.05 or less.

${ }^{*} \mathrm{P}$-value or significant value calculated from chi-square test (at $95 \%$ confidence interval and 5 degrees of freedom).

Finally, to measure the level of microbial exposure of the waste collectors, the total microbial count in the collected samples was calculated and then compared with that of the normal individuals. Findings showed that total microbial load in hands of SWCs and HWCs was $1.1 \times 10^{5}$ and $1.2 \times 10^{7}$ respectively which was higher than that of the control or normal group $\left(2.1 \times 10^{4}\right)$.

Table 5. Total microbial count in the studied samples

\begin{tabular}{clcc}
\hline Sample no. & Sample Type & Total count $\left(\mathbf{C F U} \mathbf{U}^{*} / \mathbf{m L}\right)$ & Average $(\mathbf{C F U} / \mathbf{m L})$ \\
\hline $\mathbf{1}$ & SWC & $8.5 \times 10^{4}$ & \\
$\mathbf{2}$ & SWC & $1.3 \times 10^{5}$ & $1.1 \times 10^{5}$ \\
$\mathbf{3}$ & SWC & $4.9 \times 10^{4}$ & \\
$\mathbf{4}$ & SWC & $1.7 \times 10^{5}$ & \\
$\mathbf{5}$ & HWC & $2.1 \times 10^{7}$ & $1.2 \times 10^{7}$ \\
$\mathbf{6}$ & HWC & $2.4 \times 10^{6}$ & \\
$\mathbf{7}$ & Normal people & $2.3 \times 10^{4}$ & $2.1 \times 10^{4}$ \\
$\mathbf{8}$ & Normal people & $1.9 \times 10^{4}$ & \\
\hline
\end{tabular}

${ }^{*} \mathrm{CFU}$, colony forming unit.

\subsection{Measures of Association}

Associations among the variables were calculated by chi-square test (2df, 2-tailed) and significant relationship $(\mathrm{P}<0.05)$ were found between education level and daily income, daily income and percentage of expenditure on foods, daily income and status of cell phone use, types of drinking water and disease episode in previous 30 days, types of toilet use and hand washing practices with soap. Surprisingly no significant relationship was found between the literacy rate and the status of cell phone use. From the point of qualitative observation, it was not very much uncommon in Bangladesh that working class people use mobile phone but are not literate.

\section{Discussion}

Although waste collectors are important for waste management system, there was no specialized study available regarding the waste collectors in Bangladesh. It was still unknown how much struggle they had to do for obtaining a minimum standard of living. This study aimed at revealing some of the issues. Findings showed that the proportion of children among the SWCs was higher (Table 1). This was because informal waste collection did not require any authoritative recognition and was not a sustainable source of income. So, the street children got easily 
involved in it. About one fourth of the waste collectors were female but this might not be the real picture (Table 1). It was revealed that other female members of SWCs are also involved in sorting and processing of the waste items at home. In respect of the marital status, the proportion was bigger for HWCs than that of SWCs (Table 1). Similarly, average household size of the HWCs was bigger than that of SWCs who were mainly children and peripatetic in the city (Table 2). Findings showed that the majority (94\%) of the waste collectors migrated from outside Dhaka (Table 2). The reason behind this was the opportunity of earning is better in Dhaka city than the other areas. Only $28 \%$ HWCs and $18.7 \%$ SWCs were literate which was less than the national literacy rate (74.7\%) for the people in the urban areas of Bangladesh (Table 1) (National Institute of Population Research and Training, Mitra and Associates \& ICF International, 2013). Most of the SWCs were floating people and $44 \%$ had no permanent sleeping place and many of them used to sleep at roadsides or in the parks (Table 2). The majority $(58.0 \%)$ shared a room by more than three people and the status was twice bigger $(26.7 \%)$ than the reference data for the urban people in Bangladesh (Table 2) (National Institute of Population Research and Training, Mitra and Associates \& ICF International, 2013). A significant variation was found in terms of the mobile phone use between two groups studied (Table 2). This might be associated with their access to electricity, houses and family size. Findings showed that all the HWCs had better access to electricity and they were not as floating as the SWCs (Table 2). In general, waste collectors had less access to electricity (70.0\%) than the overall accessibility (90.2\%) for people living in urban areas of Bangladesh (National Institute of Population Research and Training, Mitra and Associates \& ICF International, 2013). Findings showed that $62.7 \%$ HWCs were using gas and $37.3 \%$ were using wood or kerosene as fuel. On the other hand, $30.7 \%$ SWCs were not even involved in cooking because they were depended on food sold at roadsides or sometimes on leftover foods collected form the wastes (Table 2).

Regarding hygiene and sanitation practices, findings showed that $65.3 \%$ HWCs and $18.7 \%$ SWCs had access to the sanitary toilet facilities whereas $70.7 \%$ SWCs had no toilet facilities (Table 3). According to Bangladesh National Hygiene baseline survey of 2014, $2 \%$ of the households had no toilet facilities (ICDDR'B, 2014). In this study, we observed that most of the waste collectors (44.0\%) had no fixed source of drinking water. Drinking unpurified water $(82.7 \%)$ was found to be significantly associated $(\mathrm{P}=<0.05)$ with their morbidity status $(41.3 \%)$ in previous 30 days (Table 3). Personal hygiene practices of the waste collectors were unsatisfactory because majority was found with long and dirty fingernails (69.3\%). Only $29.3 \%$ washed hands with soap after defecation and nobody used to wear gloves, mask and apron while working (Table 4). Their poor personal hygiene practices might also be a potential risk factor for their illness.

\section{Conclusion}

Although the household waste collectors (HWCs) and the street waste collectors (SWCs) had similarity in their efforts that was to keep the Dhaka city clean and livable, there were significant differences between these two groups in terms of their socio-economic status, hygiene and sanitation practices. No significant differences were observed between HWCs and SWCs for sex, age at first marriage, literacy rate, status of room sharing for sleeping, type of fuel used, and practices of wearing gloves, mask and apron while working. However, the overall scenario represented that the household waste collectors (HWCs) were in better situation than the street waste collectors (SWCs) that provided support to reject the null hypothesis $\left(\mathbf{H}_{\mathbf{0}}\right)$ and to accept the alternative hypothesis $\left(\mathbf{H}_{\mathbf{1}}\right)$.

Findings of this research would be helpful for short and long-term planning and policy implementation to prevent and develop overall situations of waste collectors in Bangladesh. In addition, future studies are needed to improve our waste management system.

\section{Ethical Statement}

The authors state that this is an original article and it had not been submitted to any journal for publication. The data are original and the volume of data was not split to create more publications. No manipulation was done by the researchers that can create an opportunity to raise the questions to the ethics of the study.

\section{Acknowledgements}

This research was partially funded by University Grants Commission (UGC) of Bangladesh. Institute of Nutrition and Food Science, University of Dhaka provided lab facility and technical supports.

\section{Competing Interests Statement}

Authors declare no conflict of interest.

\section{References}

Ahmed, A., Khan, S., \& Alam, M. (2000). Pilot Baseline Survey in Sarail Upazila of Brahmanbaria District. Pilot baseline survey report for the Environmental Sanitation, Hygiene and Water Supply in Rural Area 
(ESHWSRA) project, prepared by UNICEF \& DPHE.

Boschi-Pinto, C., Velebit, L., \& Shibuya, K. (2008). Estimating child mortality due to diarrhea in developing countries. Bull World Health Organ, 86, 710-717. https://doi.org/10.2471/BLT.07.050054

Cointreau, S. (2006). Occupational and Environmental Health Issues of Solid Waste Management: Special Emphasis on Middleand Lower-Income Countries. Urban Papers 2, World Bank, Washington, DC.

Dewan, A. M., Kabir, M. H., Nahar, K., \& Rahman, M. Z. (2012). Urbanisation and environmental degradation in Dhaka Metropolitan Area of Bangladesh. International Journal of Environment and Sustainable Development, 11(2), 118-147. https://doi.org/10.1504/IJESD.2012.049178

Dias, S. (2008). FórumLixo e Cidadania: Catadores de Problema Social à QuestãoSócio-Ambiental. Paper presented at the First World Conference of Waste Pickers, Bogotá, March 2008.

Elo, I., \& Preston, S. (1996). Educational differentials in mortality: United States, 1979- 85. Social Science and Medicine, 42, 47-57. https://doi.org/10.1016/0277-9536(95)00062-3

Enayetullah. (1994). A Study of Solid Waste Management for Environmental Improvement of Dhaka City. Master thesis Department of URP, Bangladesh University of Engineering and Technology. Dhaka.

Graetz, B. (1995). Socioeconomic status in education research and policy. In J. Ainley, B. Graetz, M. Long, \& M. Batten (Eds.), Socioeconomic Status and School Education (pp. 23-51). Canberra: Australian Government Publishing Service.

Helen Keller International (HKI) and James P. Grant School of Public Health (JPGSPH). (2016). State of food security and nutrition in Bangladesh: 2014. Dhaka, BD: HKI and JPGSPH.

Hossain, S. (2008). Rapid Urban Growth and Poverty in Dhaka City. Bangladesh e-Journal of Sociology, 5(1).

Hoque, B. A. (2003). Hand washing practices and challenges in Bangladesh. Int J Environ Heal R, 13(1), 81-87. https://doi.org/10.3390/ijerph13010081

ICDDR'B, Water Aid Bangladesh, Policy Support Unit, MoLGRD\&C, GoB. (2014). Bangladesh National Hygiene Baseline Survey (Preliminary Report, June 2014).

Krieger, N., David, R., Williams, \& Nancy, E. M. (1997). Measuring Social Class in Public Health Research: Concepts, Methodologies, and Guidelines. Annual Review of Public Health, 18, 341-78. https://doi.org/10.1146/annurev.publhealth.18.1.341

Marks, G. (1998). Measurement of Socioeconomic Status and Social Class in the LSAY Project. Technical Report.

National Institute of Population Research and Training (NIPORT), Mitra and Associates, and ICF International. (2013). Bangladesh Demographic and Health Survey 2011. Dhaka, Bangladesh and Calverton, Maryland, USA: NIPORT, Mitra and Associates, and ICF International.

Salam, M. A. (2001). Analysis and Design of Solid Waste Management System for A Residential Zone of Dhaka City' M.Sc. Engineering Thesis, Department of Civil Engineering, Bangladesh University of Engineering and Technology. Dhaka.

Self-employed women's association (SEWA). (2010). Working in the waste and recycling sectors; opportunities and challenges for green jobs. Ahmedabad, India.

Waste Pickers without Frontiers. (2008). Report of Conference Proceedings. First International and Third Latin American Conference of Waste-Pickers. Bogotá, Colombia 1-4 March 2008.

WHO Health Statistics. (2008). Mortality and burden of diseases. Geneva, Switzerland: WHO; 2008.

Winblad, U., \& Simpson-Hebert, M. (Eds.). (2004). Ecological sanitation. Eco San Res Programme.

Wise, H. S. (1979). The food handler and personal hygiene. In G. J. Flick, Jr., et al., (Eds.), sanitation notebook for the seafood industry (p. 11-1). Department of food science and technology, Virginia polytechnic institute and state University, Blaksburg.

\section{Copyrights}

Copyright for this article is retained by the author(s), with first publication rights granted to the journal.

This is an open-access article distributed under the terms and conditions of the Creative Commons Attribution license (http://creativecommons.org/licenses/by/4.0/). 